Aims To create a one stop multi-speciality/multidisciplinary Duchenne Muscular Dystrophy (DMD) clinic working across the boundaries of the NHS and non-statutory services. To provide young men with an opportunity to engage with palliative care services as part of their holistic care.

Methods The professionals visited each other's speciality areas/ clinics and commenced a regular meeting to discuss patients in September 2019, the services then commenced a pilot clinic by reorganising existing commitments. The pilot commenced in January 2020 with patient feedback captured post clinic.

Results Despite the challenges of COVID-19, we have successfully run five clinics at Jacksplace to date reviewing 22 patients; 18 in person (four virtually). Each patient has been seen by a neuromuscular consultant, cardiologist, DMD coordinator, physio, transition CNS and palliative medicine associate specialist. The service continues to develop and now offers echocardiograms within the clinic.

The patient feedback is universally in favour of continuing in this format. All commented on the improved facilities, ease of access and that it is 'wonderful to see several professionals on the same day'.

Clinicians highlighted the benefit of this model of care leading to strong communication between professions, saving time and an ability to develop co-ordinated individual plans of care with the young men.

Conclusion Collaboration between professionals and organisations has allowed us to deliver a well co-ordinated, holistic service. It has facilitated the integration of palliative care allowing relationships to build between the multi-professional team and the young men creating a safe environment where conversations about advance care planning can become a normal part of their care.

\section{P-227 LIVING RIGHT UP TO THE END; AN ASSET-BASED COMMUNITY DEVELOPMENT APPROACH TO END-OF- LIFE SUPPORT}

${ }^{1}$ Susan High, ${ }^{2}$ Cormac Russell, ${ }^{1}$ Irene McKie. ${ }^{1}$ Strathcarron Hospice, Denny, UK; ${ }^{2}$ Nurture Development, Dublin, Ireland

10.1136/spcare-2021-Hospice.242

As specialists in palliative care, Strathcarron Hospice understands that with the right support, people with life limiting conditions, their carers and the bereaved can live well right to the end. The New Public Health Model of Palliative Care recognises that dying is not just a medical issue and that social support is often more important than medical. It promotes the importance of social relationships and encourages engagement with communities to identify the people and assets that can provide end of life support.

At Strathcarron Hospice we have adopted an Assets-Based Community Development approach to enable us to understand what communities can do for themselves, what they need a little help with, and what they need salaried professionals to do for them. We recognise that it is only when agencies start organising themselves the way that people organise their lives, instead of expecting people to organise their lives around services and silos, then true partnerships between citizens and institutional systems will emerge.

As a Nurture Development Learning site, we set out to discover the strengths and talents which exist in our local communities. Working in three diverse communities across Forth
Valley, we have created time and a safe space for citizens, associations, local practitioners and helping organisations to learn together how to make invisible assets visible and productive. We have provided opportunities to break down traditional structures that may stifle creativity.

In doing this, we have moved from the traditional model of volunteer Compassionate Neighbours towards communities where everyone's contribution is valued and people feel connected to each other. We aim to create the conditions to support citizens to come together to create a community where people who are aging, dying or grieving can be supported, with institutions (like the hospice) being there to provide specialist help when invited to do so.

\section{P-228 COMPASSIONATE NEIGHBOURS SHARING POWER AND RESOURCES WITH COMMUNITIES TO DRIVE BETTER END-OF-LIFE CARE}

${ }^{1}$ Kate Heaps, ${ }^{2}$ Nicki Shaw, ${ }^{3}$ Heather Richardson, ${ }^{1} J o n$ Devlin. ${ }^{1}$ Greenwich and Bexley Community Hospice, London, UK; ${ }^{2}$ Princess Alice Hospice, London, UK; ${ }^{3}$ St Christopher's Hospice, London, UK

\subsection{6/spcare-2021-Hospice.243}

Background Hospices are experts in end-of-life care, embedded in communities and ideally placed to share our expertise. This is the aim of Compassionate Neighbours (CNs), a well-established programme, growing across London and the South East of England.

Aims The programme aims to:

- Redefine the relationship between hospices and people suffering from social isolation/disconnection.

- Co-design and deliver support for people bereaved or coming to the end of their lives.

- Develop authentic and reciprocal relationships which penetrate the whole community.

Method

- Hospices invite people to train as CNs.

- Trained CNs are connected with community members who seek a new relationship to help them cope with loneliness arising from serious illness/end-of-life care challenges.

- CNs have access to regular support and advice from the hospice/network of CNs.

- The programme was evaluated by independent researchers and studied as part of a completed $\mathrm{PhD}$ project.

- Evaluation findings and data on demography and reach will be shared, alongside case-studies to illustrate impact.

Results

- Positive change in the wellbeing of participants, reducing loneliness, increasing connectivity and ascribing meaning and value to life.

- New social capital between the hospice and communities with power differentials challenged, participants enjoy greater agency and citizens feel increased ownership of end-of-life issues and the hospice.

- Increases in recruiting and matching CNs during COVID-19. There are now over 1,800 CNs.

Conclusions There is growing acknowledgement of morbidity and mortality related to loneliness and social isolation. CNs provide relationships and connectivity for isolated people. CNs increase their own networks, skills and death literacy. 
Community members are active players, adding value to the lives of their $\mathrm{CN}$. By engaging citizens in the challenges and opportunities afforded by death, dying and loss, relinquishing control and sharing power, hospices introduce new actors into the end-of-life arena. There is evidence that it's scalable, flexible and adaptive.

\section{P-229 ABSTRACT WITHDRAWN}

\section{P-230 ARTIFICIAL INTELLIGENCE IN PALLIATIVE CARE: A SYSTEMATIC REVIEW TO IDENTIFY ITS SCOPE OF USE}

${ }^{1}$ Osamah Ahmad, ${ }^{2}$ Sarah Stanley, ${ }^{3}$ Stephen Mason, 4,5 ${ }^{6}$ Amara Nwosu. ${ }^{1}$ University of Liverpool, Liverpool, UK; ${ }^{2}$ Marie Curie Hospice Liverpool, Liverpool, UK; ${ }^{3}$ Palliative Care Unit, Liverpool, UK; ${ }^{4}$ Lancaster Medical School, Lancaster, UK; ${ }^{5}$ Marie Curie Hospice Liverpool, Liverpool, UK; ${ }^{6}$ Liverpool University Hospitals NHS Foundation Trust, Liverpool, UK

10.1136/spcare-2021-Hospice.244

Background New technologies, such as artificial intelligence (AI), supported by novel ways of linking and analysing data, are transforming the way that healthcare data is analysed. AI is increasingly being used to support healthcare delivery, and examples of palliative care application are emerging. AI is an umbrella term covering a variety of intertwined sub-concepts: machine learning refers to machine algorithms automatically improving themselves through experience, and neural networking refers to a form of this mimicking the way the human brain works. Deep learning is another form of machine learning, and natural language processing may refer to a variety of AI algorithms used to understand text intended for human recipients. However, the current scope of (and potential) use of AI in palliative care delivery has not been fully explored. The aim of this project was to define the scope of use of AI methodologies in palliative care studies.

Methods A systematic review of literature was conducted in accordance with the PRISMA guidelines. Four electronic databases were searched, in addition to grey literature searches. AI was used as an umbrella term to include keyword searches for the following: machine learning, deep learning, neutral networks and natural language processing.

Results Twenty-seven relevant articles were selected. The majority of studies described people with cancer $(n=10$, $37 \%)$, from general palliative $(n=8,30 \%)$ and intensive care populations $(n=4,15 \%)$. Studies using natural language processing were most common $(n=12,44 \%)$, with others mainly utilising machine learning $(n=10,37 \%)$, deep learning $(n=3$, $11 \%)$ and neural network $(n=2,8 \%)$ methodologies. A variety of outcomes were covered, with most studies predicting survival $(n=8,30 \%)$, identifying goals of care $(n=6,22 \%)$, analysing serious illness conversations $(n=2,9 \%)$ and reporting if palliative care best practice recommendations had been followed in clinical care $(n=2,9 \%)$.

Conclusion Most palliative care AI studies report cancer, use natural language processing and machine learning methods, to predict survival and analyse goals of care. Future studies need to explore how different AI methods can support palliative care, whilst carefully assessing the risks and limitations, to ensure effective use in the management of serious illness.

\section{P-231 THE QUALITY IMPROVEMENT METHODOLOGY USED TO CREATE DAFFODIL STANDARDS- TO IMPROVE END-OF- LIFE CARE}

${ }^{1}$ Catherine Millington-Sanders, ${ }^{2}$ Eve Barnes, ${ }^{3}$ Julie Pearce. ${ }^{1}$ Royal College of General Practitioners, London, UK; ${ }^{2}$ Great Western Hospitals NHS Foundation Trust, Swindon, UKi ${ }^{3}$ Marie Curie, London, UK

\subsection{6/spcare-2021-Hospice.245}

Background Most palliative care is provided by GPs and wider palliative care and community services (Mitchell, Loew, Millington-Sanders, et al., 2016). The Daffodil Standards (DS) were created in order to provide a free, accessible, evidencebased support around end-of-life care (see: https://www.rcgp. org.uk/clinical-and-research/resources/a-to-z-clinical-resources/ daffodil-standards/introduction.aspx). This work presents the quality improvement (QI) methodology used to establish an ongoing, national level process that helps engage practices in working to improve end-of-life care through QI and reflective practices.

Aims

- Supporting GP practices and Primary Care Networks, to provide high quality end-of-life care across their populations.

- Offering a structured approach - minimising variation in endof-life care experienced.

- Supporting GP teams - learning and development.

- Improving equity.

- Connecting GP care within compassionate community development (see: https://www.rcgp.org.uk/clinical-andresearch/resources/a-to-z-clinical-resources/daffodil-standards/ the-daffodil-standards/standard-8-general-practice-being-hubswithin-compassionate-communities.aspx).

Methods The QI methodology of Diagnose, Plan and Test, Implement and Embed, Sustain and Spread (NHS England, 2019) has been employed to evidence, establish and continually improve the Daffodil Standards.

Results The process:

Diagnose

- Review of learning from policy and research for gaps.

- Review of GP QI programmes/curriculum for scale service improvements to support general practice.

- Triangulation matrix between end-of-life care 'Ambitions', Istatements, GP qualitative research and feedback.

Plan and Test

- Development of draft DS headings.

- Consultation with end-of-life care partners.

- Reviewed from 9 to 8 core DS based on feedback.

- Organisational sign-off.

Implement and Embed

- Launch February 2019.

- Connected with England end-of-life care QOF 19/20.

Sustain and Spread (including developments)

- COVID-19 learning.

- Development of Older People's Care Home Standard.

- End-of-life care GP lead review from each nation to make more devolved nation accessible.

- Refresh of the Daffodil Standards.

- RCGP end-of-life care suite of webinars 2021.

- Planned evaluation 2021/22.

Conclusions This review of processes demonstrates how QI methodologies can be used on a national level to support 